\title{
REPORTS
}

\section{The Cuban Olympiad in Informatics: A New Stage from the DMOJ Online Judge}

\author{
Francisco HERNÁNDEZ GONZÁLEZ", \\ José Daniel RODRÍGUEZ MORALES', \\ Dovier Antonio RIPOLL MÉNDEZ ${ }^{3}$ \\ ${ }^{1}$ Instituto Preuniversitario Vocacional en Ciencias Exactas de Villa Clara, Cuba \\ ${ }^{2}$ Mantainer of DMOJ-UCLV online judge, Cuba \\ ${ }^{3}$ General Director of ICPC Caribbean, Cuba \\ e-mail:ipvce@uclv.edu.cu,josedanielr@yandex.com,dovierripoll@gmail.com
}

\begin{abstract}
The Cuban Olympiad in Informatics is a competition promoted by the Ministry of Education of the Republic of Cuba and among its objectives is to encourage the study of programming and algorithms in students of pre-university education. The competition has different stages ranging from the school level to the national contest. In recent years, the programming competition has been renewed with the use of an instance of the Don Mills Online Judge, an open-source online judge. This has allowed the event to be held simultaneously from all the country's provinces, which has been a challenge for students and teachers from the participating Cuban schools.
\end{abstract}

Keywords: grading systems, programming competitions, competitors, Cuban Olympiad in Informatics, informatics education, training.

\section{Introduction}

In Cuba, academic contests began to be developed since the 1960s, with the aim of motivating students and teachers to promote interest in studying the subjects of each discipline, encouraged by emulation with their peers in the different levels of education and regions. 
The Ministry of Education of the Republic of Cuba is the main responsible for organizing, coordinating and executing knowledge and skills competitions at all educational levels.

Cuba began to develop informatics contests in education from the beginning of the 80 's with the introduction of minicomputers in Vocational Schools. Then it continued with the introduction of microcomputers in the Exact Sciences high schools, and later, by stages, to all schools in the country. From the 90 s on, events of this type really gained in strength in the whole country. With the annual holding of the International Olympiad in Informatics (IOI), since 1989, this activity gained in levels of organization and quality.

Currently, the academic contest format consists of different levels of competition: at the school, municipal, provincial and national levels. Based on the results in the national contest, a group of students is chosen to make up the National Preselection; in it, intensive work is being carried out to train, evaluate and finally choose the team that will represent to Cuba in the IOI and the Ibero-American Informatics and Computing Competition (CIIC by its acronym in Spanish).

The Cuban Olympiad in Informatics (OCI by its acronym in Spanish), also known as the National Computing Contest, is an event where participate the top-10 students from each province and the special municipality of Isla de la Juventud, all belonging to the pre-university education. The OCI is a competition that takes place in the first quarter of the year, simultaneously in all the country's provinces, one venue per province. It consists of two days of exam. In each one, three problems of algorithmic nature must be solved. Ten students compete in each competition venue, representing the three groups into which the pre-university is divided (tenth, eleventh and twelfth grades).

\section{Informatics Contests in Cuba}

In Cuba, although it has been extended to all educational levels from primary to preuniversity schools, the teaching of the informatics does not include programming and algorithms, so it is necessary to teach it through complementary programs. The teaching of $\mathrm{C} / \mathrm{C}++$ programming language is the most widespread among those who show an interest in solving algorithmic problems.

The stage prior to the national contest are the provincial contests, which currently focus on solving problems of an algorithmic nature, through a programming language. The bases for its realization are defined by the group of provincial coaches and the competition is not managed by an online judge in all provinces. In the first competition stage, at the school level, it is recommended to apply math-logic tests and later train the winners in a programming language, data structures and algorithms.

Informatics contests have undergone organizational changes over the years, in search of raising the quality of work. These changes are governed by the IOI syllabus, with some adjustments between each school year. The students can participate in other complementary competitions, including the friendly-contests between Pre-University Vocational Institutes in Exact Sciences (IPVCE), as well as the ICPC university events. 
The National Contest consists of two days of competition with three problems each day. Solutions are evaluated against test cases. After experimenting with different organizational variants since 2003, the contest is held in single-venues in each province of the country where a supervisor (proctor), defined by the Ministry of Education, ensures that all competition rules are met.

With the best-ranked students, the winners of the National Contest, a National Preselection is formed, which basically consists of a face-to-face training camp for intensive preparation from which the students who later represent Cuba at the IOI and the CIIC are defined. On the other side, the group of coaches who work with these students is selected according to the results of their students in national events, the academic level of the teachers and the willingness to dedicate themselves to a job that requires many hours of work per day.

Throughout this process, the link with the ICPC Competitive Programming Movement, at the university level, has been of vital importance; among the main achievements are included:

- Participation in the different stages of national university competitions.

- Participation in the Cups organized by the universities.

- Taking advantage of the experience of competitors and university coaches.

- Carrying out trainings led by university students.

- Participation of ICPC coaches in the pre-university competitions as judges.

- The use of online judges created by universities to complement the training of pre-university students.

\section{Online Judges as Tools for Contestants' Trainning and Evaluation}

The Online judges (Revilla et al., 2008) play an important role in the preparation of the contestants, as well as in conducting programming competitions for them. They usually contain problem descriptions, an automated system for submitting and grading solutions, conducting competitions, analyzing solutions, and forums for discussing solutions from wherever the contestants are located.

The Caribbean Online Judge (COJ) is an online judge developed at the University of Informatics Sciences (UCI by its acronym in Spanish), in Havana, to contribute to the preparation of competitors/teams for the ICPC competitions. The overlapping of many of the problems in the COJ, with the topics of pre-university contests, made such a tool among the preferences for the preparation of pre-university students. Arteaga (2016) developed a module that increased the functionality of the COJ allowing partial evaluation, both in its 24-hour archive and in the execution of a new format of competitions with IOI rules.

For many years, Cuban national contests were held offline and without instant feedback during the tests. The solutions grading, at the end of the competitions, was carried out manually using checker programs and a grader to verify the correct use of the running time and memory space. 
The above mentioned module for IOI evaluations (Arteaga, 2016), added to the COJ, improved the grading process of the Contests and, of course, the general performance of competitions. But it was necessary to improve the efficiency in the application of the National Computing Contest, therefore an analysis of different types of judges for algorithmic competitions (Erdősné et al., 2018) were done.

For this, a review of several of the existing open-source online judges were carried out, such as: HUSTOJ, Sharif-Judge, Vjudge (its license changed and it is no longer free software), Ejudge, Mooshak, BNUOJ and DMOJ. The aim was finding the most appropriate for its deployment and to be used for grading the submissions in a similar way as it is done at the IOI.

Finally, the Don Mills Online Judge ${ }^{1}$ was chosen because it had many desirable features and also support for the pre-university competitions, such as:

- It is an active and quite mature project.

- Simple and modern interface.

- Good documentation.

- Possibility of interacting with the developers team.

- Support for a wide variety of languages.

- Good performance and stability.

- Partial scoring.

- Batch evaluation.

- Contests with time windows.

- Virtual competitions.

- Ratings system.

- Comments.

\section{* DM:OJ Problems submissions USERS CONTESTS about}

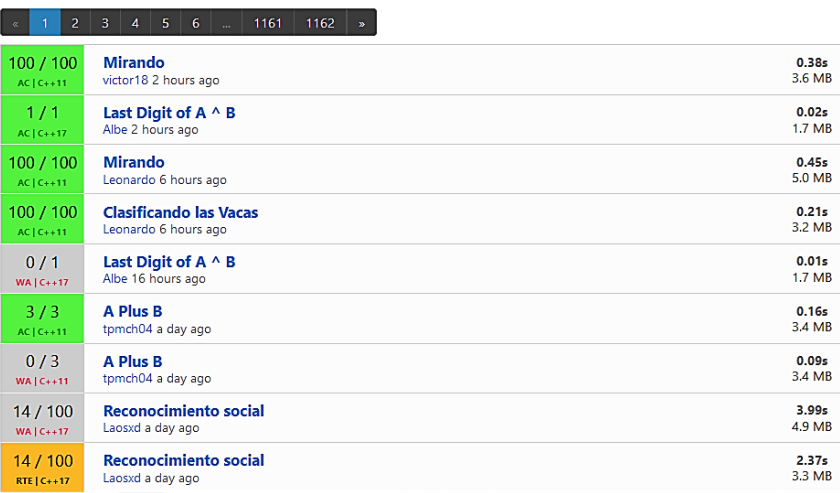

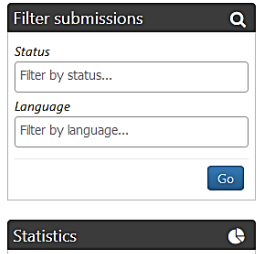

Fig. 1. Submissions view of the DMOJ.

\footnotetext{
${ }^{1}$ https://github.com/DMOJ/online-judge
} 
- Editorial support.

- Language-specific time and memory constraints.

- User rating charts.

- Blog on the main page.

- Support for private competitions.

After the judge deployment it was possible to hold several competitions demonstrating its stability; later, new problems were activated for the 24-hour archive. In 2019, all the necessary regulations were made to begin to carry out the online National Computer Contest simultaneously throughout the country.

\section{The DMOJ-UCLV Online Judge}

The DMOJ-UCLV² site has all the site's components deployed in a Virtual Private Server (VPS) in the main datacenter of the Central University "Marta Abreu" of Las Villas (UCLV by its Spanish acronym). At this time, for its operation it has 8 GB of RAM and an AMD Opteron 6136 processor with a frequency of $2.40 \mathrm{GHz}$ and 8 virtual cores, but these capacities may vary depending on the demand of the site. During competitions with high user participation, such as national competitions, these capacities tend to increase and in times of low activity, such as vacations, infrastructure administrators tend to reduce resources.

The current DMOJ version is number 1 , which already has $\sim 2$ years old and the dev team is working on upgrading it to the most recent version (2.1). When this process is complete, the site will be migrated to a container architecture instead of a simple virtual machine as it is now. This will make the platform easier to operate, maintain, and increase the stability.

The DMOJ has an administration interface based on WordPress which is very intuitive and is divided into several modules, among them are:

- Problems: for managing all the problems of privileged user since its elaboration to its publication. From there, all the memory and time constraints of a problem are defined. It allows a problem to have multiple authors, curators (a differentiation to give other administrators the possibility to refine the problem without appearing as authors) and testers (users who cannot modify the problem, but can submit and validate that test cases and restrictions are all correct).

- Submissions: from this module, all submissions made to the system are managed, it has several filters to reduce the list of submission to a set of interest. From here, an admin can send one or more submissions to be re-judged, as well as give a verdict manually (in problems that require it). It also includes the configuration of the languages and judges that will be available.

- Contests: allows the management of the competitions and their details such as date, duration, time window, problems, rating, users who may or may not participate, etc.

\footnotetext{
${ }^{2}$ https://dmoj.uclv.edu.cu/
} 


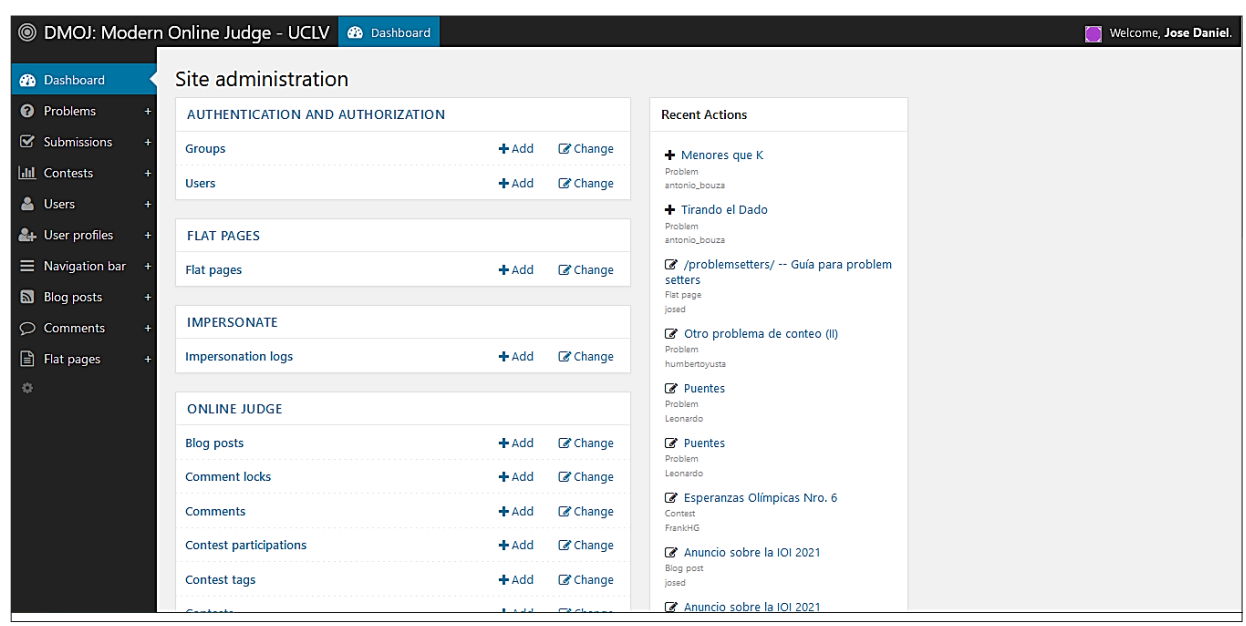

Fig. 2. Main view of the administration interface.

- Users: module for managing users, authentication credentials and permissions.

- User profiles: management of user and organization profiles. From here, the admin can view all registered users and some related metadata.

- Blog: management of the blog found on the main page, from here new entries are edited and the existing ones can be changed.

\subsection{System Architecture}

The site is made up of several services with different responsibilities that collaborate with each other, most of them are written in Python programming language. The main component is the web application developed with Django framework.

The other fundamental part is the judges, who are in charge of evaluating each submission sent to the online judge; they must be configured to be able to compile and execute programs written in multiple programming languages. The judges process one submission at a time, and usually multiple instances of the judges are spawned to avoid that many submissions accumulate in the queue, and also that if one of the judges fails, the system is not disrupted.

There are also other auxiliary services such as the judges' bridge and the event server. The first serves as a coordinator between the web application and the multiple instances of judges; the bridge also acts as a dispatch queue and is responsible for notifying the response backwards. The second is who allows the client to receive updates in real time in their browser, while each of the test cases is evaluated until the final verdict of the submission; this component is developed with Node.js.

The other services are typical components of any web service, such as the MySQL database engine and the NGINX web server with uWSGI. 


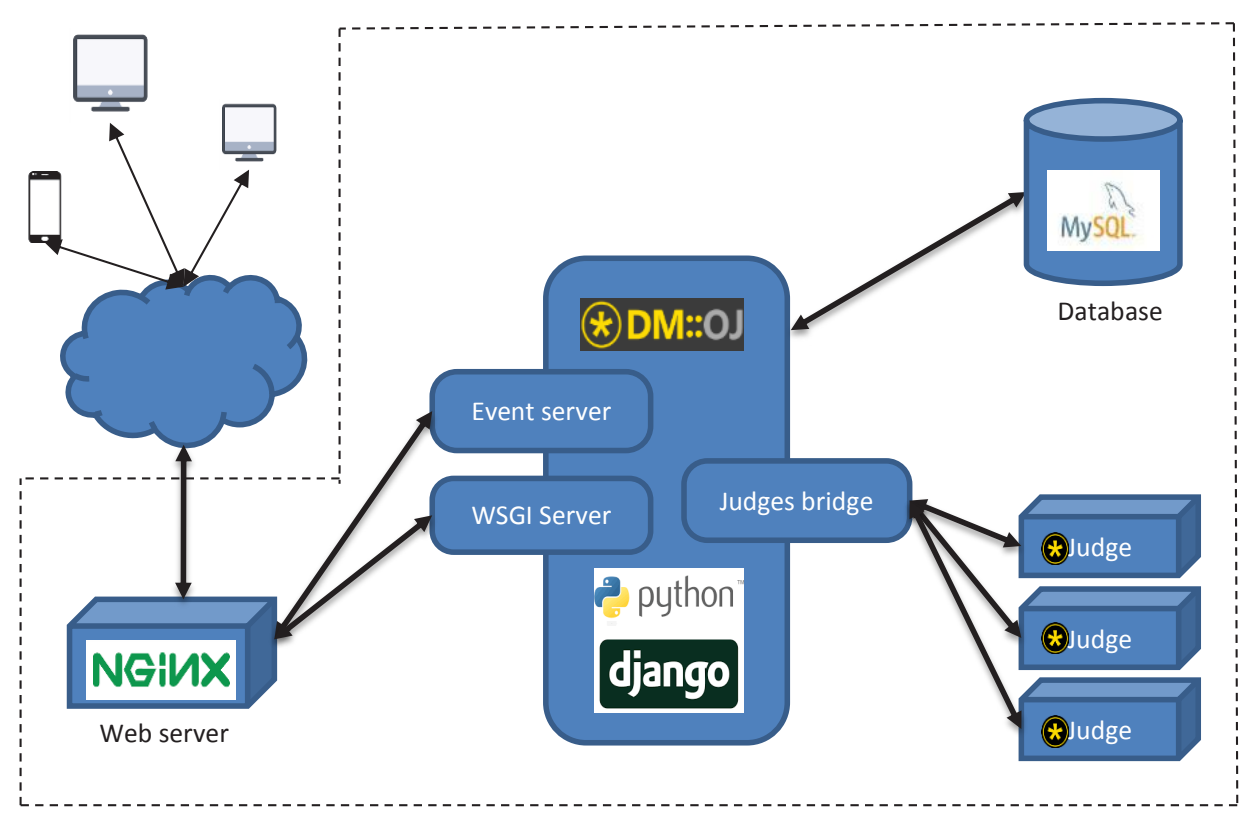

Fig. 3. Representation of the system architecture and components.

\subsection{Statistics / Facts}

At the end of March 2021 there are 407 public problems in the DMOJ-UCLV, most of which are taken from other sources and reused in training competitions. A non-negligible part of them belongs to authentic problems published for the first time on this site, whose authors are students and professors from both universities and pre-university. Those problems have been used in official competitions such as university cups and national competitions.

There are also 633 active users and 103 competitions have been held, mainly at the pre-university level.

There are 10 programming languages available for submitting the solutions; the system maintainers are willing to add support for new requested languages. Currently supported languages are Awk, C, C++ (03, 11, 17), Assembly, Java, Lua, Pascal, Perl, Python and Scala.

A total of 58034 submissions have been made, predominantly in the $\mathrm{C}++$, Java and Python languages, distributed as follows according to the verdict: .
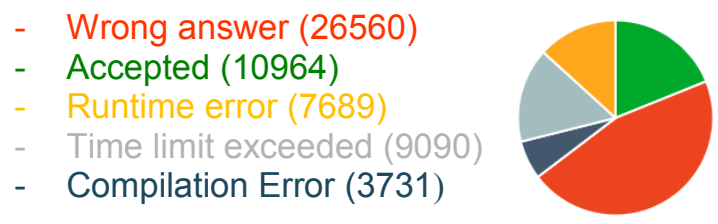
In 2019, for the first time in Cuba, a pre-university National Computer Olympiad was held online. In the year 2020, it was held on that way for the second time. The DMOJUCLV online judge was used on both occasions.

This constituted a milestone for students and teachers, because for the first time in OCI history all competed simultaneously from their institutions, obtaining immediate feedback on the answers sent in each problem. In addition, the online competition allowed them to know the final results of the competition within a few hours after its culmination and facilitated the work of the human judges in charge of the competition evaluation.

The experience of these two years of national online contests has been very positive. Despite having more than 150 users competing simultaneously, no instability was reported on the platform and the main difficulties occurred at the competing venues with logistic issues.

\section{Conclusions}

The DMOJ-UCLV has become a fundamental virtual space for high school contestants and coaches who want to train for competitions. Also, it becomes in the official host of National computer competitions and other competitive programming events in Cuban high schools.

The adoption of the online judge for the Cuban Olympiad in Informatics is a step forward to keep the contests as an attractive and motivating activity for students, while it has brought new challenges to the organizers to continue improving the quality of these events.

\section{References}

Arteaga Salgado, F.R. (2016). Módulo para juzgar soluciones con las reglas de la Olimpiada Internacional de Informática en el Juez Caribeño en Línea. Trabajo de Diploma par a optar por el título de Ingeniero Informático.

Erdősné Németh, Á., Zsakó, L. (2018). Grading Systems for Algorithmic Contests. Olympiads in Informatics, 12 , 159-166. DOI: 10.15388/ioi.2018.13.

Hernández González, F. (2008) "Metodología para el entrenamiento de los estudiantes de preuniversitario que participan en concursos de informática". Tesis en opción del grado cientifico de doctor en Ciencias Pedagógicas Universidad Central "Marta Abreu” de Las Villas.

Revilla M. A., Manzoor S., Liu R. (2008). Competitive Learning in Informatics: The UVa Online Judge Experience. Olympiads in Informatics, 2008, 2, 131-148. 


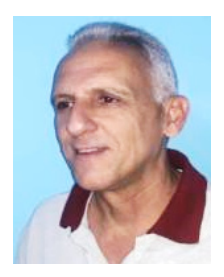

F. Hernández González is an informatics teacher at the Pre-University Vocational Institute in Exact Sciences of Villa Clara. He has attended ten IOIs and has worked within the group that has coordinated the national informatics competitions. Since 1991 he has participated in the selection and preparation of Cuban students for the IOI. He received the degree of Doctor of Pedagogical Sciences at the Central University "Marta Abreu" of Las Villas for his work in the selection and development of students with programming talent.

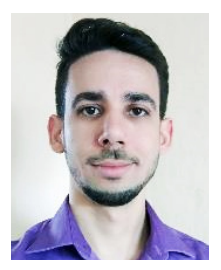

J.D. Rodríguez Morales is a Computer Science graduate from Universidad Central de Las Villas (UCLV), Santa Clara, Villa Clara, Cuba, in 2015. He has experience as a computer science instructor at UCLV where he taught in several programming and algorithms related courses. He was involved in many ICPC activities and was coach of several teams during his time as an instructor at UCLV. He is the current maintainer of DMOJ-UCLV and collaborator of preuniversity informatics events.

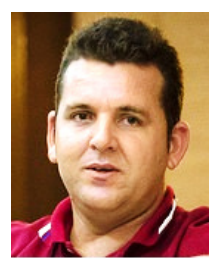

D.A. Ripoll Méndez has an Engineering in Informatics Sciences from the University of Informatics Sciences (UCI), Havana, Cuba, in 2008. He has experience as a Professor of Analysis and Design of Algorithms. The ICPC Executive Director for the Caribbean region, since the year 2009 to now. Co-Founder of the Caribbean Online Judge (COJ). He has been involved in the organization and realization of dissimilar activities related to the teaching of computer programming for early-age learners. He has collaborated with the inclusion of Cuba in the Bebras worldwide initiative. Since 2005, he has collaborated with the development of the pre-university Informatics Olympiads in Cuba. 
